
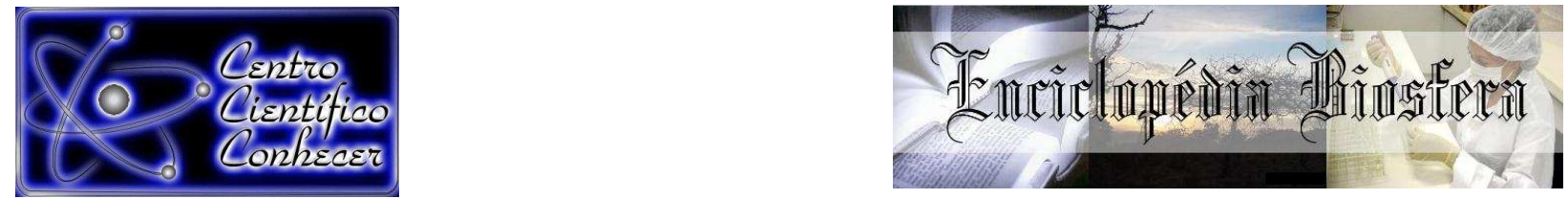

\title{
AVALIAÇÃO FÍSICO-QUÍMICA E MICROBIOLÓGICA DE MÉIS DE ABELHAS COMERCIALIZADOS NO MUNICÍPIO DE SOURE - MARAJÓ - PARÁ
}

Paulo Wender Portal Gomes ${ }^{1}$, Abraão de Jesus Barbosa Muribeca ${ }^{1}$, Maria Dulcimar de Brito Silva ${ }^{2}$, João da Silva Carneiro ${ }^{3}$, Ronilson Freitas de Souza ${ }^{3^{*}}$.

1.Graduandos em Licenciatura Plena em Ciências Naturais com Hab. em Química Campus XIX - Salvaterra - Marajó-PA.

2. Mestre em Química. Professora do Curso de Licenciatura Plena em Ciências Naturais da Universidade do Estado do Pará.

3. Doutores em Química. Professores do Curso de Licenciatura Plena em Ciências Naturais da Universidade do Estado do Pará. *E-mail: ronilson@uepa.br

Recebido em: 08/09/2015 - Aprovado em: 14/11/2015 - Publicado em: 01/12/2015 DOI: http://dx.doi.org/10.18677/Enciclopedia_Biosfera_2015_013

\begin{abstract}
RESUMO
Este trabalho teve como objetivo avaliar as características físico-químicas e microbiológicas de amostras de méis de abelhas comercializados no município de Soure - Ilha do Marajó - Pará. Doze amostras de méis foram analisadas através dos parâmetros físico-químicas e microbiológicas. Obtendo-se os seguintes resultados: umidade (18,81 a 24,04\%), $\mathrm{pH}\left(3,35\right.$ a 4,00), acidez livre $\left(15,50\right.$ a 42,50 meq. $\left.\mathrm{kg}^{-1}\right)$, açúcares redutores (49 a 73\%), cor predominante foi âmbar-claro (42\%), teor de fenóis $(15,73-64,99 \mathrm{mg}(\mathrm{EAG}) / 100 \mathrm{~g}$ mel). Todas as amostras estavam dentro dos limites estabelecidos pela legislação em vigor para os parâmetros microbiológicos. Entretanto, todas as amostras apresentaram sujidades. Diante destes resultados, sugere-se a adoção de boas práticas apícolas para os produtores de forma a assegurar uma boa qualidade higiênico-sanitária dos méis comercializados na cidade de Soure.
\end{abstract}

PALAVRAS-CHAVE: Amostras comerciais, Controle de qualidade, Parâmetros físico-químicos e microbiológicos

\section{PHYSICO-CHEMICAL AND MICROBOLOGICAL EVALUATION OF HONEY BEE MARKETED IN THE MUNICIPALITY OF SOURE - MARAJÓ - PARÁ}

\begin{abstract}
This study objective was evaluate the physicochemical and microbiological characteristics of samples of honey sold in the town of Soure - Marajó Island, Pará. Twelve samples of honey were analyzed for the physicochemical and microbiological parameters. Obtaining the following results: moisture (18.81 to $24.04 \%), \mathrm{pH}$ (3.35 to 4.00 ), free acidity (15.50 to $\left.42.50 \mathrm{meq} \cdot \mathrm{kg}^{-1}\right)$, reducing sugars (49 to $73 \%$ ), predominant color was amber light (42\%), phenol content (15.73 to $64.99 \mathrm{mg}$ (EAG)/100g honey). All samples were within the limits set by law for microbiological parameters. However, all samples showed dirt. Given these results, we suggest the
\end{abstract}


adoption of good beekeeping practices for producers in order to ensure good sanitary conditions of honey marketed in Soure city.

KEYWORDS: Commercial samples, Physicochemical and microbiological parameters, Quality control

\section{INTRODUÇÃO}

O mel é o adoçante mais antigo utilizado pelo homem, tendo em sua composição a predominância dos açúcares glicose e frutose (KUROISHI et al., 2012). Quando somadas suas frações monossacarídicas, chega-se a média representativa de $65 \%$ da sua composição total (SILVA et al., 2009a). É um produto natural que resulta do processamento do néctar das flores e partes extraflorais, feito por enzimas digestivas específicas das próprias abelhas, sendo armazenado e amadurecido em favos de suas colmeias para servir-lhes de alimento (ESCOBAR \& XAVIER, 2013).

Devido seu apreciável sabor e valor energético, o mel é um produto amplamente consumido em todo mundo. É comum encontrar variações nos valores das propriedades físicas e químicas, pois vários fatores interferem na sua qualidade, como espécie de abelha, disponibilidade de recursos florais, composição química do solo, condições climáticas da região, processamento e condicionamento (GÓIS et al., 2013). Nos últimos anos, trabalhos científicos com méis de abelhas (GÓIS et al., 2013, SCHLABITZ et al., 2010; SOUZA et al., 2010; MATOS et al., 2011; RICHTER et al., 2011; SANTOS et al., 2011; SOUZA et al., 2012a; SOUZA et al., 2012b MENEZES et al., 2014) visam traçar um perfil físico-químico e microbiológico que subsidie um monitoramento adequado de ações de controle de qualidade, visando à produção de méis mais competitivos em um mercado cada vez mais exigente. Além de monitorar as ocorrências de fraudes e/ou alterações na composição dos méis oriundas do processamento e/ou armazenamento inadequado,

A utilização do mel não deve se limitar apenas as suas propriedades adoçantes e nutricionais, mas por este se tratar de um alimento funcional, proporciona benefícios à saúde, como, por exemplo, a prevenção e tratamento de doenças crônico-degenerativas (BERTOLDI et al., 2012). KRPAN et al. (2009) e HUSSEIN et al. (2011) atribuem que a capacidade antioxidante do mel se dá em virtude da presença de compostos fenólicos, que desempenham um papel na inibição dos efeitos deletérios causados pelos radicais livres advindos do desequilíbrio funcional de um organismo. A quantificação do teor de compostos fenólicos em méis de abelhas pode servir de indicativo para empregar os melhores produtos na aplicação na apiterapia, que é o uso clínico dos produtos apícolas na prevenção e/ou tratamento de doenças.

Segundo a Associação Brasileira dos Exportadores de Mel (ABEMEL, 2015), a produção brasileira exportou aproximadamente 25,32 toneladas de mel no ano de 2014, mantendo o Brasil no Ranking dos maiores produtores mundiais de mel e seus subprodutos apícolas. A produção de mel na região do Marajó-PA ainda é baixa, pois a maioria dos apicultores ainda pratica a apicultura de forma extrativista, utilizando técnicas rudimentares como o esmagamento dos favos a próprio punho e filtração do mel em tecidos inadequados, bem como o armazenamento em recipientes reutilizado (Figura 01 ).

Existem alguns microrganismos (bolores, leveduras e bactérias) advindos do processo de obtenção e processamento da matéria-prima que conseguem resistir ao fator osmótico exercido pela alta concentração de açúcares presente no mel, mas 
não interferem na integridade do produto e nem são patogênicos (SOUZA, 2010). Contudo, as ínfimas condições de higiene empregadas no processo de beneficiamento e a contaminação das áreas em torno da colmeia, são indicadores de irregularidade sanitária, o que poderá oferecer risco à saúde dos consumidores (MATOS et al., 2011; GÓIS et al., 2013).

Dessa forma, este trabalho objetivou determinar as características físicoquímicas e microbiológicas de méis de abelhas comercializados na cidade Soure Marajó - PA, visando subsidiar informações que contribuam para ações de controle de qualidade do mel produzido na região do Marajó-PA.

\section{MATERIAL E MÉTODOS}

\section{Área de estudo e amostras}

O município de Soure, Estado do Pará, está localizado na mesorregião do Marajó, microrregião Arari, latitude 0043'00" sul e longitude 48ำ1'24" oeste; estando a $10 \mathrm{~m}$ de altitude e à distância de $80 \mathrm{~km}$ da capital paraense, Belém. Segundo dados do IBGE (2015), sua população estimada até o fim de 2015 será de 24.286 habitantes.

O presente estudo foi desenvolvido com doze amostras de méis de abelhas (FIGURA 1) adquiridas através da compra direta no comércio local do referido município. Posteriormente, as amostras foram conduzidas aos Laboratórios de Tecnologia de Alimentos e Microbiologia da Universidade do Estado do Pará, Campus XIX-Salvaterra.

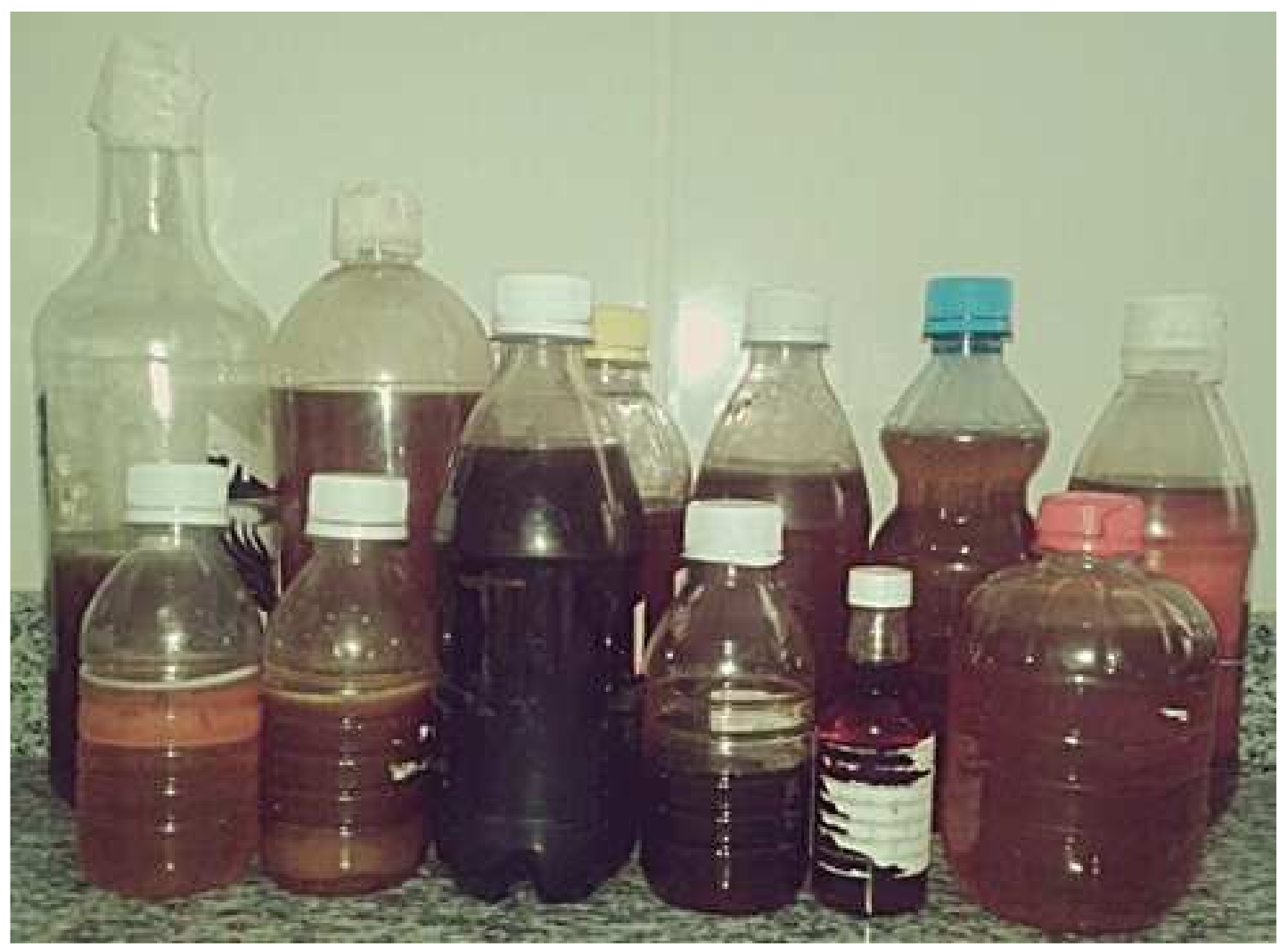

FIGURA 1 - Amostras de méis comercializados no município de Soure - PA, acondicionadas em suas respectivas embalagens de origem. 


\section{Análises físico-químicas}

Determinação de umidade

A determinação de umidade no mel foi obtido em triplicata pelo método refratométrico da AOAC (2000) - método 969.38b. Este método consiste na determinação do índice de refração do mel a 20ำ que é convertido para o conteúdo de umidade através de uma tabela de referência, a qual fornece a concentração como uma função do índice de refração. Fez-se a calibração do refratômetro utilizando água destilada, posteriormente adicionou-se duas gotas da amostra de mel e realizou-se a leitura, levando em conta o reajuste do valor lido, devendo-se acrescentar 0,00023 para cada grau acima de $20^{\circ} \mathrm{C}$, ou subtrair para cada grau abaixo.

\section{Quantificação de açúcares redutores}

Os açúcares redutores (AR) foram determinados pelo método do ácido 3,5dinitrossalicílico (ADNS) de acordo com SOUZA (2010). O teste de ADNS baseia-se na reação entre o açúcar redutor e o ácido 3,5-dinitrosalicílico, que é reduzido a um composto de coloração avermelhada, o ácido 3-amino-5-nitrosalicílico. A intensidade desta cor é medida a $540 \mathrm{~nm}$, sua absorbância é diretamente proporcional à concentração de AR presente na solução original. No momento da análise foi preparada uma solução de mel $2 \mathrm{mg} / \mathrm{mL}$. Alíquota de $0,2 \mathrm{~mL}$ desta solução foi misturada com 1,3 $\mathrm{mL}$ de água destilada e $1 \mathrm{~mL}$ do reagente ADNS, esta mistura foi aquecida a $100{ }^{\circ} \mathrm{C}$ durante 5 minutos, em seguida, ad icionado $10 \mathrm{~mL}$ de água destilada. Esta mistura foi realizada a $540 \mathrm{~nm}$ em espectrofotômetro (Belphotonics $\left.\AA^{\circledR}\right)$.

\section{Potencial hidrogeniônico $(\mathrm{pH})$}

$\mathrm{O} \mathrm{pH}$ foi determinado com auxílio de um phmetro da marca Novainstruments $\AA$, previamente calibrado. No momento da análise, $2,0 \mathrm{~g}$ de mel foi diluido em $15 \mathrm{~mL}$ de água deionizada, em seguida foi realizada a leitura (AOAC, 2000).

\section{Acidez livre}

Os ácidos orgânicos totais presentes nos méis foram determinados de acordo com o método oficial da AOAC (2000); o qual baseia na titulação da amostra com solução de $\mathrm{NaOH} 0,05 \mathrm{~N}$, até atingir o $\mathrm{pH}=8,5$; método recomendado pelo Regulamento Técnico de Identidade e Qualidade do mel (BRASIL, 2000). Uma massa de $2 \mathrm{~g}$ foi transferida para um erlenmeyer de $250 \mathrm{~mL}$ com auxílio de $15 \mathrm{~mL}$ de água deionizada, como indicador foi usado duas gotas de fenolftaleína $1 \%(\mathrm{~m} / \mathrm{v})$. A solução foi titulada com hidróxido de sódio $0,05 \mathrm{~N}$ até atingir um $\mathrm{pH}=8,5$. Para 0 cálculo da acidez utilizou-se a fórmula: $A c i=(V \times f c \times N \times 1000) / A$, onde $V=$ volume gasto de solução de $\mathrm{NaOH} 0,05 \mathrm{~N}(\mathrm{~mL}) ; \mathrm{fc}=$ fator de correção da solução de $\mathrm{NaOH}$ (adimensional); $\mathrm{A}=$ massa da amostra $(\mathrm{g}) ; \mathrm{N}=$ concentração normal da solução de $\mathrm{NaOH}$, os valores foram expressos em $\mathrm{mqEg} / \mathrm{Kg}$. 
Determinação da Cor

As determinações de cor das amostras de méis foram foram realizadas de acordo com o método descrito por Bianchi (1981), a $635 \mathrm{~nm}$ de uma solução $50 \%$ $(\mathrm{m} / \mathrm{v})$ de mel em água deionizada. Após a diluição, a solução foi mantida em repouso durante 15 minutos antes da leitura no espectrofotômetro (Bel-photonics $®$ ). Os valores encontrados foram interpretados em cor segundo a escala de Pfund.

Teor de fenóis totais

O teor de fenóis foi realizado pelo método descrito por Silici et al. (2010) utilizando-se o reagente de Folin-Ciocalteau. Foram preparadas soluções de méis em água destilada na concentração de $50 \mathrm{mg} / \mathrm{mL}$. Alíquota de $0,5 \mathrm{~mL}$ dessa solução foi misturada com 2,5 mL de reagente de Folin-Ciocalteau $10 \%$ e, após 5 minutos, acrescentou-se $2 \mathrm{~mL}$ de carbonato de sódio 7,5\% recém preparado. A mistura foi homogeneizada e deixada em repouso por 2 horas. Em seguida foi realizada a leitura em $760 \mathrm{~nm}$. O ácido gálico foi utilizado como padrão. Os resultados foram expressos em mg de equivalentes de ácido gálico (EAG)/100 g de mel.

\section{Análises microbiológicas}

Contagem de bolores e leveduras

Para a contagem de bolores e leveduras utilizou-se a técnica de semeadura em superfície, utilizando meio de cultura GPA da marca Fluka® (15 g/L de Agar; 20 $\mathrm{g} / \mathrm{L}$ de Dextrose e $4 \mathrm{~g} / \mathrm{L}$ de Extrato de levedura) e incubado invertido por 5 dias a 25은 C. A contagem das colônias seguiu normas descritas nos "Procedimentos para a contagem de colônias" (BRASIL, 2003), os resultados foram expressos em UFC/g.

Contagem de coliformes totais e termotolerantes

Esta análise foi realizada através da técnica de fermentação em tubos múltiplos proposto por BRASIL (2003), sendo inicialmente realizado o teste presuntivo utilizando o caldo lauryl sulfato triptose (LST) para incubação das diluições, mantidos a uma temperatura de $37^{\circ} \mathrm{C}$ por 48 horas. Para os tubos da série LST que apresentaram resultados positivos (formação de gás no interior do tubo de Durham) foi realizado o teste confirmatório utilizando o caldo verde bile brilhante para coliformes a $35^{\circ} \mathrm{C}$ e o caldo Escherichia coli para termotolerantes a $45{ }^{\circ} \mathrm{C}$. O número mais provável $(\mathrm{NPM} / \mathrm{g})$ foi obtido a partir no número de tubos positivos pela tabela de Hoskins.

\section{Análise microscópica}

Para análise microscópica, buscando identificar a presença de possíveis sujidades (órgãos de abelhas, cera, vestígios vegetais, etc) nas amostras, foi preparada uma lâmina contendo uma gota de mel, juntamente com uma gota de fucsina, em seguida foi observada a um microscópico óptico. Os resultados foram registrados via imagens fotográficas (SOUZA et al., 2012a). 


\section{RESULTADOS E DISCUSSÃO}

Os valores médios dos parâmetros físico-químicos (umidade, acidez livre, pH, açúcares redutores e Fenóis Totais) das doze amostras de mel comercializadas no município de Soure-PA (Figura 02). Verifica-se que o valor médio de umidade foi de $21,53 \%$, valor acima do recomendado pelas legislações brasileira (BRASIL, 2000) e internacional (CODEX, 2001).

A quantidade de água presente no mel pode influenciar consideravelmente na sua qualidade, onde $58,33 \%$ das amostras analisadas excedem o valor máximo permitido pelas legislações vigentes, que sugerem um valor máximo de $20 \%$; valores acima do estabelecido comprometem a qualidade do mel de abelha, uma vez que favorece o crescimento de microrganismo patogênicos. BETTAR et al. (2015) ao analisarem 27 amostras de mel, constataram um índice de reprovação de 10\%. Segundo SAXENA et al. (2010) o alto teor de água pode levar a fermentação indesejável do mel durante o armazenamento, causada pela ação de leveduras. Este fator pode estar correlacionado com os métodos de extração e/ou com as etapas de processamento do produto.

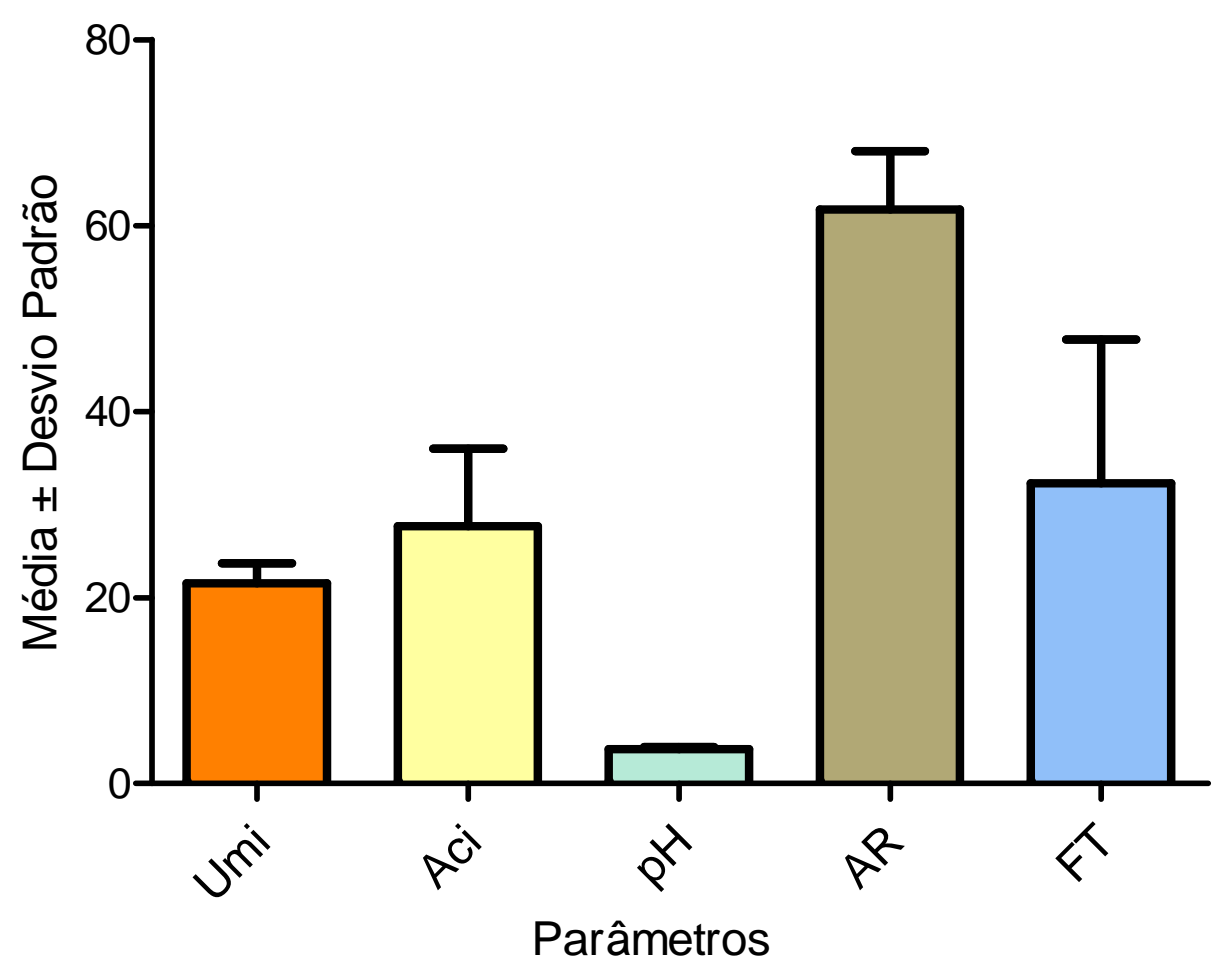

FIGURA 2 - Padrão médio dos parâmetros (Umi: Umidade (\%), Aci: Acidez livre (meq. $\mathrm{kg}^{-1}$ ), $\mathrm{pH}$ : Potencial Hidrogeniônico, AR: Açucares Redutores (\%) e FT: Fenóis Totais mg $(E A G) / 100 \mathrm{~g}$ de mel) das doze amostras de mel analisadas

Os valores médios obtidos para açucares redutores foram $61,75 \%$, com faixa de variação de 49 - 73\% (TABELA 01). As amostras M01, M03, M04 e M12 apresentaram-se abaixo do padrão permitido pela legislação nacional (BRASIL, 2000), que determina um valor mínimo de $65 \%$ e internacional (CODEX, 2001) com 
um mínimo de 60\%. Assim, 33,33\% das amostras estão fora dos padrões para açúcares redutores. RICHTER et al., (2011), ao estudarem 19 amostras de méis produzidas na cidade de Pelotas, Rio Grande do Sul, constataram que 10,5\% das amostras analisadas estavam em desacordo com a legislação nacional (BRASIL, 2000) e 5,2\% com a internacional (CODEX, 2011). Segundo MENDES et al. (2009) a proporção de açúcares presentes no mel determina sua viscosidade, densidade, higroscopicidade e cristalização.

TABELA 1 - Resultados ( ${ }^{a}$ média $\pm{ }^{b}$ desvio padrão) dos parâmetros físico-químicos das amostras de méis do município de Soure - PA.

\begin{tabular}{|c|c|c|c|c|c|}
\hline Amostras & Umi & Aci & $\mathrm{pH}$ & AR & FT \\
\hline M01 & $23,85 \pm 0,10$ & $30,00 \pm 1,47$ & $3,47 \pm 0,10$ & $58,00 \pm 1,12$ & $35,96 \pm 0,61$ \\
\hline M02 & $22,78 \pm 0,20$ & $17,50 \pm 1,69$ & $3,81 \pm 0,11$ & $73,00 \pm 1,02$ & $23,90 \pm 0,81$ \\
\hline M03 & $18,97 \pm 0,10$ & $12,50 \pm 1,68$ & $3,92 \pm 0,20$ & $56,00 \pm 0,88$ & $23,46 \pm 1,58$ \\
\hline M04 & $23,33 \pm 0,30$ & $20,00 \pm 1,70$ & $3,67 \pm 0,15$ & $58,00 \pm 1,44$ & $19,00 \pm 0,69$ \\
\hline M05 & $19,09 \pm 0,44$ & $25,00 \pm 0,50$ & $3,65 \pm 0,66$ & $61,00 \pm 1,45$ & $18,03 \pm 1,40$ \\
\hline M06 & $22,78 \pm 0,23$ & $30,00 \pm 0,10$ & $4,00 \pm 0,34$ & $63,00 \pm 0,80$ & $20,50 \pm 0,88$ \\
\hline M07 & $19,61 \pm 0,15$ & $30,00 \pm 1,05$ & $3,78 \pm 0,45$ & $64,00 \pm 0,15$ & $27,86 \pm 2,48$ \\
\hline M08 & $22,78 \pm 0,85$ & $30,00 \pm 0,05$ & $3,86 \pm 0,10$ & $63,00 \pm 0,01$ & $15,73 \pm 1,76$ \\
\hline M09 & $23,05 \pm 0,10$ & $35,00 \pm 0,70$ & $3,79 \pm 0,05$ & $66,00 \pm 0,03$ & $48,79 \pm 0,87$ \\
\hline M10 & $18,81 \pm 0,97$ & $42,50 \pm 1,27$ & $3,35 \pm 0,01$ & $61,00 \pm 0,45$ & $47,55 \pm 1,87$ \\
\hline M11 & $19,29 \pm 0,55$ & $25,00 \pm 1,22$ & $3,81 \pm 0,05$ & $69,00 \pm 0,66$ & $64,99 \pm 0,23$ \\
\hline M12 & $24,04 \pm 0,50$ & $35,00 \pm 0,98$ & $3,36 \pm 0,48$ & $49,00 \pm 0,77$ & $41,80 \pm 0,81$ \\
\hline Méd. & 21,53 & 27,70 & 3,70 & 61,75 & 31,43 \\
\hline Mín. & 18,81 & 15,50 & 3,35 & 49,00 & 15,73 \\
\hline Máx. & 24,04 & 42,50 & 4,00 & 73,00 & 64,99 \\
\hline${ }^{1}$ Leg. & $\leq 20,0$ & $\leq 50,0$ & * & $\geq 65$ & * \\
\hline${ }^{2}$ Leg. & $\leq 20,0$ & $\leq 50,0$ & 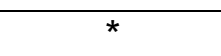 & $\geq 60$ & * \\
\hline
\end{tabular}

${ }^{a}$ :média das três repetições, ${ }^{b}$ Desvio padrão da média, AR: Açucares Redutores (\%); pH: Potencial Hidrogeniônico; Aci: Acidez livre (meq. $\mathrm{kg}^{-1}$ ); Umi: Umidade(\%); FT: Fenóis Totais $\mathrm{mg}(\mathrm{EAG}) / 100 \mathrm{~g}$ de mel $(760 \mathrm{~nm})$; Cor $\left(\mathrm{Abs}_{635}\right)$; ${ }^{1} \mathrm{Leg} .:$ Legislação Brasileira (BRASIL, 2000); ${ }^{2}$ Leg.: Legislação Internacional (CODEX, 2001); * ausência de limites nas legislações;

O valor médio de pH encontrado para as 12 amostras foi de 3,70, com variação de 3,35 - 4,00 (Tabela 01). $\mathrm{O}$ pH do mel pode estar diretamente relacionado à composição florística e a composição do solo nas áreas de coleta, assim como depende das associações de espécies vegetais para a composição final do produto e substâncias mandibulares, das abelhas, acrescidas ao néctar (GÓIS et al., 2013).

Segundo SOUZA (2010) baixos valores de pH são considerações importantes em relação à ação antimicrobiana, visto que a grande maioria de organismos patogênicos necessitam de uma faixa de $\mathrm{pH}$ maior que 7 para se reproduzir. Em contrapartida, SILVA et al. (2008) demonstram preocupação com uma faixa de pH muito baixa, pois a acidificação do substrato pode acelerar a desidratação das hexoses promovendo a formação do 5-hidroximetilfurfural (HMF), que é um dos produtos da degradação do mel, o que resulta na perda de sua qualidade para os 
mais diversos fins. Segundo LEAL et al. (2001), o pH do mel de abelhas indica o estado de conservação e qualidade deste produto que é naturalmente ácido, com valores normais entre 3,3 e 4,6. Quando esses Valores de pH são muito baixos, podem indicar adulteração por xarope de sacarose ou amido invertido por hidrólise ácida, enquanto valores muito altos evidenciam caldas de sacarose sem adição de ácido, desta forma o mel passou pelo processo de fermentação ou que este foi adulterado provocando a formação de HMF em alta quantidade.

Os valores encontrados para acidez total em meq $/ \mathrm{kg}$ mostram que todas amostras estão de acordo com os valores estabelecidos pela legislação nacional (BRASIL, 2000) e internacional (CODEX, 2001), com variação de 15,50 - 42,50 $\mathrm{meq} / \mathrm{kg}$, com média de 27,70 meq $/ \mathrm{kg}$ (Tabela 01). ALMEIDA-FILHO et al. (2011), examinaram oito amostras de méis comercializados no município de Pombal - PB, verificaram que todas estavam dentro dos limites pré-estabelecidos pelas legislações vigentes para acidez livre. SANTOS \& OLIVEIRA (2013) relataram valor médio de acidez $38,51 \mathrm{meq} / \mathrm{kg}$, variação de $24,41-49,97 \mathrm{meq} / \mathrm{kg}$, destacando que a grande variação pode estar possivelmente relacionada à composição do néctar ou, em menor influência, às condições dos solos. Sugerindo a conclusão de que, como o mel é proveniente do néctar de várias flores, este vai conferir-lhe características específicas, embora se considere também que o manejo e as condições climáticas tenham suas contribuições.

As cores encontradas para as doze amostras estão dentro dos padrões da legislação nacional (BRASIL, 2000), que estabelece uma variação que vai desde o branco-água até o âmbar-escuro. Pela interpretação dos resultados obtidos na figura 3 , verificou-se a predominância da cor âmbar-claro representando $42 \%$ das amostras. Em seu estudo SOUZA (2010) encontrou para 10 amostras de méis do Estado do Pará, a predominância da cor extra-branco (30\%), o que pode estar relacionada com o tipo de flor, néctar, vegetação etc.

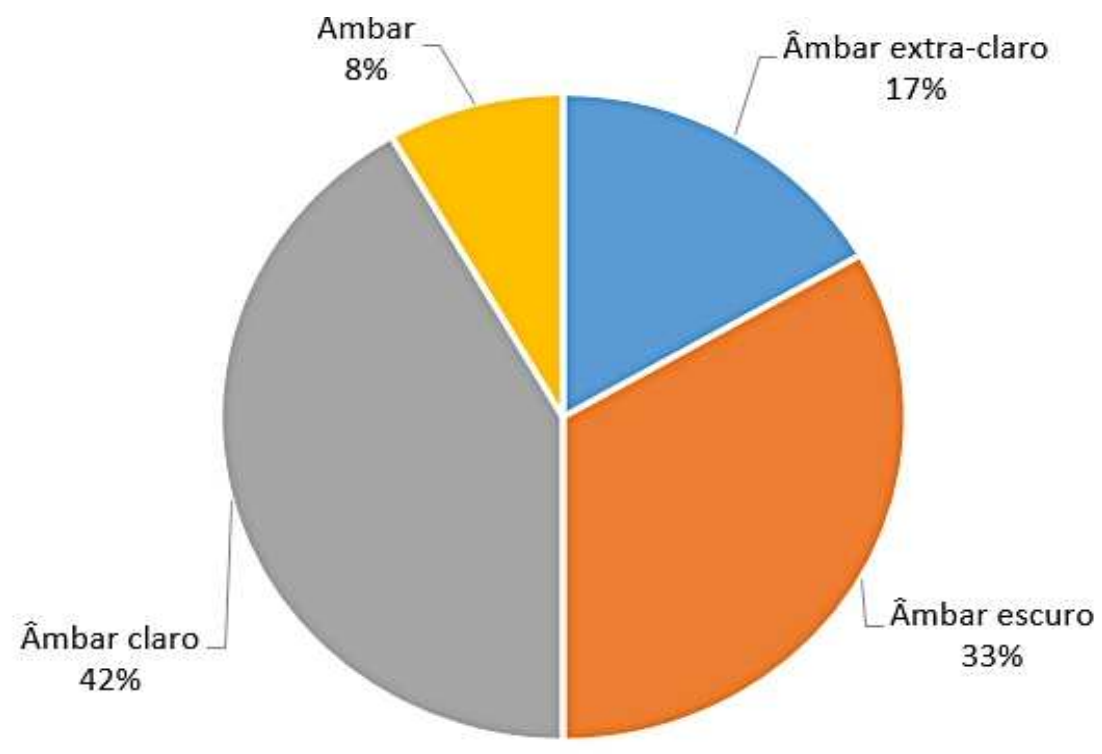

- Âmbar extra-claro " Âmbar escuro " Âmbar claro " Âmbar

FIGURA 3 - Representação percentual da variação da cor das amostras de méis comercializados no município de Soure - Marajó - Pará. 
A cor é considerada um indicador de qualidade do mel, visto que méis mais claros têm uma melhor aceitação no mercado nacional e internacional. $O$ escurecimento de mel pode estar associado ao tempo de armazenamento, assim como às condições de temperaturas exaustivas que pode promover a formação de HMF e à contaminação por metais (ALVES et al., 2005).

Para os resultados do teor de fenóis totais, verificou-se um valor mínimo de 15,73 e máximo de $64,99 \mathrm{mg}(\mathrm{EAG}) / 100 \mathrm{~g}$ mel, apresentando valor médio de 31,43. Esses valores se assemelham ao teor encontrado por MESQUITA et al. (2012), que ao analisarem amostras de méis das cidades de Itaparé e Granja, Estado do Ceará, encontraram valores de 20,02 e 55,34 mg, respectivamente. MENEZES et al. (2014), encontraram valores variando de 30,15 a 56,30 mg (EAG). Em estudos do teor fenólico de méis do Estado de Roraima mostram valores entre 25 a 50,9 mg para cada $100 \mathrm{~g}$ de mel (PONTIS et al., 2014). Os compostos fenólicos vêm sendo objetos de pesquisas e reportados como possuidores de importantes propriedades, incluindo atividade anti-inflamatória, estrogênica, inibidora enzimática e antitumoral (HUSSEIN et al., 2011).

De todas as amostras analisadas, é pertinente a comparação da coloração e do teor total de fenóis, onde se percebeu que os quatro maiores valores encontrados estão presentes nos méis de tonalidade mais escura (âmbar-escuro). RIBEIRO et al. (2015), ao analisarem o teor de compostos fenólicos em seu trabalho, constataram a mesma relação comparativa, o que implica à conclusão de que quanto mais escuro o mel, maior será seu teor de fenólicos totais.

Quanto à qualidade microbiológica, os resultados mostram que nenhuma das amostras analisadas verificou-se a presença de microrganismos do grupo coliformes, dispensando a necessidade de realização dos testes para EC. A legislação Nacional (BRASIL, 2000) e Internacional (CODEX, 2001) não exigem a realização de testes microbiológicos em mel, entretanto estabelecem o padrão máximo permitido equivalente a $<3,0 \mathrm{NMP} / \mathrm{g}$, sugerindo que sejam seguidas boas práticas higiênico-sanitárias nas etapas de extração, manipulação, processamento e armazenamento do produto.

SANTOS et al. (2011) desenvolveram um trabalho no qual os valores coincidem com os resultados aqui encontrados, apresentando valores abaixo de $<3,0 \mathrm{NMP} / \mathrm{g}$, estando em conformidade com a legislação. SOUZA et al. (2012a), ao avaliarem as características microbiológicas de 21 méis produzidos na Região Nordeste do Estado da Bahia encontraram valores <3,0 NMP/g.

Para contagem padrão de bolores e leveduras, foi possível observar que das 12 amostras, apenas duas apresentaram unidades formadoras de colônia, mas são valores desconsideráveis. Porém, ao estudarem a qualidade microbiológica de méis produzidos na Paraíba, MELO et al. (2011) detectaram uma alta presença de bolores e leveduras em até $14,2 \times 10^{2}$ UFC/g. NERIS et al. (2013), também encontraram valores parecidos em méis comercializados no estado do Maranhão com resultados superiores a 738 (UFC/g).

As amostras de méis comercializadas em Salvaterra - Marajó - PA, município vizinho a Soure mostram que $70 \%$ apresentaram contaminação por fungos e leveduras e $80 \%$ das amostras também apresentaram valores elevados para bactérias aeróbias mesófilas (MODESTO JUNIOR et al., 2014). Diante disso, os méis comercializados na cidade de Soure possuem melhor qualidade higiênicosanitária de que os méis comercializados na cidade de Salvaterra. 
Para as análises microscópicas pode-se inferir que geralmente as amostras apresentam sujidades (FIGURA 4) algumas decorrentes do processo natural de obtenção da matéria-prima feito pelas próprias abelhas e outras são decorrentes das técnicas de extração, que ainda são rudimentares. Nessa segunda, o mel é extraído pelo "esmagamento" dos favos, o que implica inevitavelmente na contaminação por órgãos do inseto, vestígios de cera etc. SOUZA et al. (2012b), ao analisarem cinco amostras da região do Vale Médio do Araguaia não encontraram partículas estranhas além daquelas de sua composição natural (grão de pólen, partículas de areia, larvas etc.), e ainda afirma que isso não afeta a qualidade primária do mel.

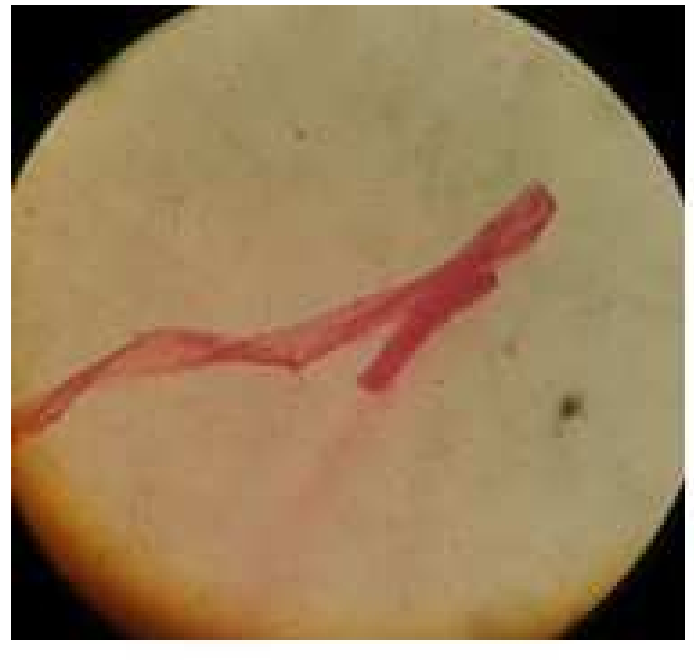

A

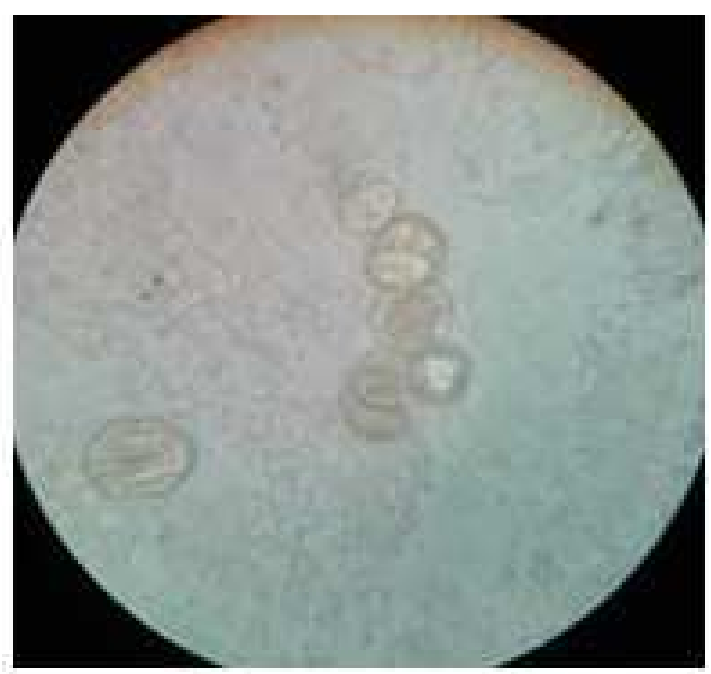

B

FIGURA 4 - A) pernas de abelha, B) grãos de pólen, colorizado com fucsina fenicada artificialmente - aumento 400x.

\section{CONCLUSÕES}

A maioria das amostras avaliadas apresentaram valores para os parâmetros físico-químicos e microbiológicos dentro dos padrões do Regulamento Técnico de Identidade e Qualidade do Mel (Ministério da Agricultura e do Abastecimento) e legislação internacional.

Entretanto, todas as amostras de méis apresentaram sujidades, havendo necessidade de realização de cursos de capacitação em extração e processamento de mel com o intuito de melhorar o nível tecnológico dos apicultores e meliponicultores marajoaras.

\section{REFERÊNCIAS}

ABEMEL. Mercado Mundial de Mel Disponível em http://www.agricultura.gov.br/arq editor/file/camaras setoriais/Mel e produtos apic olas/36RO/ICA 36RO.pdf. Acessado em 06 setembro 2015.

ALMEIDA FILHO, J. P.; MACHADO, A. V.; ALVES, F. M. S.; QUEIROGA, K. H.; CÂNDIDO, A. F. M. Estudo físico-químico e de qualidade do mel de abelha 
comercializado no município de Pombal - PB. Revista Verde, v. 6, n. 3, p. 83 - 90, 2011.

ALVES, R. M.; CARVALHO, C. A. L.; SOUZA, B. A.; SODRÉ, G.S.; MARCHINI, L.C. Características físico-químicas de amostras de mel de Melipona mandaica Smith (Hymenoptera: Apidae). Ciência e Tecnologia de Alimentos, v. 25, n. 4, p. 644-50, 2005.

AOAC. ASSOCIATION OF OFFICIAL ANALYTICAL CHEMISTS. Official Methods of Analysis of AOAC International. 17th. v. II. 2000.

BERTOLDI, F. C.; GONZAGA, L. V.; FETT, R.; REIS, V. D. A. Avaliação da atividade de antioxidante e determinação de compostos fenólicos totais de méis produzidos no pantanal. Revista Evidência, v. 12, n.2, p. 155 - 164, 2012.

BETTAR, I.; GONZÁLES-MIRET, M. L.; HERNANZ, D.; MARCONI, A.; HEREDIA, F. J.; TERRAB, A. Characterisation of Moroccan Spurge (Euphorbia) honeys by their physicochemical characteristics, mineral contents and colour. Arabian Journal of Chemistry, In Press, p. 3-9, 2015.

BIANCHI, E. M. La miel, características y composición - Análisis y Adulteraciones. Santiago del Estero: UNSE - CEDIA, 1981

BRASIL. Ministério da Agricultura. Instrução normativa $\mathrm{n}^{\circ}$ 11, de 20 de outubro de 2000. Estabelece o regulamento técnico de identidade e qualidade do mel. Diário Oficial da República Federativa do Brasil, Poder Executivo, Brasília, DF, 23 out. Seção 1, p. 16-17.2000.

Ministério da Agricultura e do Abastecimento. Instrução Normativa nº 62, de 26 de agosto de 2003. Métodos Analíticos Oficiais para Análises Microbiológicas para Controle de Produtos de Origem Animal e Água. Diário Oficial da União, de 18 de setembro de 2003, Seção 1, Página 14, 2003.

CODEX Alimentarius. Revised Codex Standard for Honey. Codex Stan 12-

1981. Codex Alimentarius Commission. Rev. 2 (2001).

ESCOBAR, A. L. S.; XAVIER, F. B. Propriedades fisioterápicas do mel de abelhas. Revista Uningá, Maringá, n. 37, p.159-172, 2013.

GÓIS, G. C.; LIMA, C. A. B.; SILVA, L. T.; EVANGELISTA-RODRIGUES, A.. Composição do mel de Apis mellifera: requisitos de qualidade. Acta Veterinaria Basilica, v. 7, n. 2, p. 137-147, 2013.

HUSSEIN, S. Z.; YUSOFF, K. M.; MAKPOL, S.; YUSOF, Y. A. M. Antioxidant capacities and total phenolic contents increase with gamma irradiation in two types of malasyan honey. Molecules, n.16, p. 6378-95, 2011.

IBGE (2015). Municíopio de Soure, Pará. Disponível em:

http://www.cidades.ibge.gov.br/xtras/perfil.php?lang=\&codmun=150790. Acessado em 06 setembro de 2015. 
KRPAN, M.; MARKOVIC, K.; SARIC, G.; SKOKO, B.; HRUSKAR, M.; VAHCIC, N. Antioxidant activities and total phenolics of acacia honey. Czech Journal of Food Sciences, v. 27, p. 244-7, 2009.

KUROISHI, A. M. QUEIROZ, M. B.; ALMEIDA, M. M.; QUAST, L. B. Avaliação da cristalização de mel utilizando parâmetros de cor e atividade de água. Journal of Food Technology, Campinas, v. 15, n. 1, p. 84-91, 2012.

LEAL, V. M.; SILVA, M. H.; JESUS, N. M. Aspecto físico-químico do mel de abelhas comercializadas no município de Salvador, Bahia. Revista Brasileira de Saúde e Produção Animal, v. 1, p. 14-18, 2001.

MATOS, I. T. S. R.; NUNES, M. T.; MOTA, D. A.; LAUREANO, M. M. M. Qualidade microbiológica do mel de Melipona sp. produzido na Amazônia Central (Parintins AM - Brasil). Revista Verde, v.6, n. 4, p. 91-5, 2011.

MELO, F. S. N.; ALMEIDA, J. C.; MARTINS, W. F.; ARAUJO, A. S. Qualidade microbiológica de méis produzidos e comercializados no alto Sertão paraibano. I Semana Acadêmica de Engenharia de Alimentos de Pombal. Pombal, 2011.

MENDES, C. G.; SILVA, J. B. A.; MESQUITA, L. X.; MARACAJÁ, P. B. As análises do mel: revisão. Caatinga, v. 22, p. 7-14, 2009.

MENEZES, M. G. G.; LIBERATO, M. C. T. C.; COSTA, E. F.; SILVA, L. R.; LIMA, S. M.; VASCONCELOS, V. C. S. Análise quantitativa dos teores de fenóis totais, flavonóides e anti-radical livre por DPPH de amostras de méis de diferentes regiões do Ceará. In: 54º Congresso Brasileiro de Química, Natal-RN, 2014.

MESQUITA, W. S.; LIBERATO, M. C. T. C.; BRAGA, D. C.; Estudo comparativo do teor de fenóis totais, flavonóides e atividade antioxidante de Melipona subnitida D. e Apis mellifera L. produzidos no Ceará. In: 52 Congresso Brasileiro de Química, Recife-PE, 2012.

MODESTO JUNIOR, E. N.; GOMES, P. W. P.; MURIBECA, A. J. B.; ASSIS, R. N.; SOUZA, R. F. Perfil sensorial e de qualidade do mel comercializado no município de Salvaterra - Ilha do Marajó - Pará. Enciclopédia Biosfera, v. 10, n. 19, p. 1448-57, 2014.

NERIS, M. S.; LACERDA, L. M.; RABÊL, H. P. S. M.; LIMA, L. M. Ocorrência de bolores e leveduras em méis comercializados informalmente no Estado do Maranhão. Nutrire, v.38, p. 439-439, 2013.

PONTIS, J. A.; COSTA, L. A. M. A.; SILVA, S. J. R.; FLACH, A. Color, phenolic and flavonoid content, and antioxidant activity of honey from Roraima, Brazil. Food Science and Technology, n. 34, p. 69-73, 2014. 
RIBEIRO, J. G.; PIRES, P. S. S.; BRANDÃO, T. M.; SILVA, R. A. Fenólicos totais e atividade antioxidante de méis de abelha de diferentes floradas. Revista Nutritime, v. 12. n. 1, p. 3903-09, 2015.

RICHTER, W.; JANSEN, C.; VENZKE, T. S. L.; MENDONÇA, C. R. B.; BORGES, C. D. Avaliação da qualidade físico-química do mel produzido na cidade de Pelotas/RS. Revista Alimentos e Nutrição, v. 22, n. 4, p. 547-553, 2011.

SANTOS, D. C.; OLIVEIRA, E. N. A. Características físico-químicas e microbiológicas de méis de Apis mellifera L. provenientes de diferentes entrepostos. Comunicata Scientiae, v. 4 n. 1, p. 67-74, 2013.

SANTOS, D. C.; OLIVEIRA, E. N. A.; MARTINS, J. N.; ALBUQUERQUE, E. M. B. Qualidade físico-química e microbiológica do mel de Apis melífera comercializado na cidade de Russas, CE. Tecnologia e Ciência Agropecuária, v.5, n.1, p.41-45, 2011.

SAXENA, S.; GAUTAM, S.; SHARMA, A. Physical, biochemical and antioxidant properties of some Indian honeys. Food Chemistry, n. 2, p. 391-397, 2010.

SCHLABITZ, C.; SILVA, S. A. F.; SOUZA, C. F. V. Avaliação De Parâmetros FísicoQuímicos e Microbiológicos em Mel. Revista Brasileira de Tecnologia Agroindustrial, v. 4, n. 1, p. 80-90, 2010.

SILICI, S.; SAGDIC, O.; EKICI, L. Total phenolic content, antiradical, antioxidant and antimicrobial activities of Rhododendron honeys. Food Chemistry, v.121, p. 238-243 L, 2010.

SILVA, L. R.; VIDEIRA, R.; MONTEIRO, A. P.; VALENTÃO, P.; ANDRADE, P. B. Honey from Luso region (Portugal): Physicochemical characteristics and mineral contents. Microchemical Journal, v. 93, n.1, 73-77, 2009a.

SILVA, R. A.; AQUINO, I. S.; RODRIGUES, A. E.; SOUZA, D. L. Análise físicoquímica de amostras de mel de abelhas Zamboque (Frieseomelitta Varia) da região do Seridó do Rio Grande do Norte. Revista Verde, v.4, n.4, p. 70-5, $2009 \mathrm{~b}$.

SILVA, S. J. N.; SCHUCH, P. Z.; VAINSTEIN, M. H.; JABLONSKI, A. Determinação do 5-hidroximetilfurfural em méis utilizando cromatografia eletrocinética capilar micelar. Ciência e Tecnologia de Alimentos, Campinas, n. 28, p. 46-50, 2008.

SOUZA, L. S.; BARBARA, M. F. S.; SODRÉ, G. S.; SANTOS, P. C.; ALMEIDA, A. M. M.; CARVALHO, C. A. L. Qualidade microbiológica do mel de Apis mellifera (Hymenoptera: Apidae) produzido na Região Nordeste do Estado da Bahia. Magistra, v. 24, n. esp., p. 194-199, 2012a.

SOUZA, F. G.; RODRIGUES, F. M.; RODRIGUES, L. G. S. M. Análise do mel de pequenos produtores do vale do médio Araguaia-Tocantins. Enciclopédia Biosfera, v.8, n.15, p. $101-08,2012 b$. 
SOUZA, R. F. Parâmetros físico-químicos, bioquímicos e microbiológicos como descritores de qualidade e discriminação dos méis do Estado do Pará. 2010. Dissertação (Mestrado em Química) - Universidade do Estado do Pará, Belém. 